\title{
Survey Analysis of Engineering Graduate Students' Perceptions of the Skills Necessary for Career Success in Industry and Academia
}

\section{Ms. Catherine G.P. Berdanier, Purdue University, West Lafayette}

Catherine G.P. Berdanier is a Ph.D. student in the School of Engineering Education at Purdue University. She earned her B.S. in Chemistry from The University of South Dakota and her M.S. in Aeronautical and Astronautical Engineering from Purdue University. Her current research interests include graduate-level engineering education, including inter- and multidisciplinary graduate education, innovative and novel graduate education experiences, global learning, and preparation of graduate students for future careers.

\section{Ms. Sara E Branch, Purdue University, West Lafayette}

Sara E. Branch is a graduate student in the Department of Psychological Sciences. She studies motivation in the context of academic and career choices.

\section{Mrs. Jeremi S London, Purdue University, West Lafayette \\ Mr. Benjamin Ahn, Purdue University, West Lafayette \\ Dr. Monica Farmer Cox, Purdue University, West Lafayette}

Monica F. Cox, Ph.D. is an Associate Professor in the School of Engineering Education and is the Inaugural Director of the College of Engineering's Leadership Minor at Purdue University. She also serves as the Executive Director of the International Institute for Engineering Education Assessment (i2e2a). She obtained a B.S. in mathematics from Spelman College, a M.S. in industrial engineering from the University of Alabama, and a Ph.D. in Leadership and Policy Studies from Peabody College of Vanderbilt University. Her teaching interests relate to the professional development of graduate engineering students and to leadership, policy, and change in STEM education. Primary research projects explore the preparation of graduate students for diverse careers and the development of reliable and valid engineering education assessment tools. She is a NSF Faculty Early Career (CAREER) and Presidential Early Career Award for Scientists and Engineers (PECASE) recipient. 


\title{
Survey Analysis of Engineering Graduate Students' Perspectives on the Skills Necessary for Career Success in Industry and Academia
}

\begin{abstract}
The current research explores doctoral students' perspectives on the skills that are essential to career success as an engineering Ph.D. Past research has explored essential skills for engineering $\mathrm{Ph}$.D.- holders, primarily using reports and ratings from those who have earned a Ph.D. in engineering and are currently working in industry or academia. This body of work has been influential in determining what faculty members believe are the skills that graduate students should develop during their educational training. However, graduate students' willingness to participate in opportunities to develop those skills is likely to depend on what skills they perceive as essential to their career success and important for them to develop during graduate studies. The current study builds on prior work (Authors, 2011): Using coded interview responses from 40 engineering Ph.D. professionals working in either industry or academia, the researchers designed a survey to explore what skills graduate engineering students believe are necessary for career success and to what degree they believe those skills should be developed during their graduate training. The initial survey included 91 items. For each item, participants indicated 1) the degree to which they believed the listed skill was important to their future successful job performance and 2) how well their Ph.D. program had prepared them in that area. This paper describes the trends that resulted from analyzing participants' responses to the survey items and identifies the skills that graduate students perceive as most important to their future career success. The findings of this study will be used to assess agreement between graduate students and engineering professionals regarding what skills are necessary for future careers. This research has practical implications for curricular improvements in doctoral engineering education and can be used to modify courses and methods of instruction to help students recognize and build the skills essential for career success.
\end{abstract}

\section{Introduction}

Misalignment of desired competencies for engineers and the skills that engineering graduates possess upon graduation is a well-studied problem, especially at the undergraduate level. ABET accreditation requires that certified engineering undergraduate programs follow a strict set of criteria for education of undergraduate engineers, such that graduates possess a certain set of skills to advance into careers in industry ${ }^{1}$. The National Research Council additionally notes the importance of preparing undergraduate students for global industry careers. ${ }^{2}$ The recent meeting of the Transforming Undergraduate Engineering Education Workshop, held by the American Society for Engineering Education, collected data from industry and academic engineering professionals in order to better understand the knowledge, skills, and attributes (KSAs) most necessary for career success, and the relative responsibilities of professionals in academia and industry to provide engineering students with these skills. ${ }^{3}$

The misalignment between desired attributes and achieved skills extends further than undergraduate engineering. It is reasonable to assume that the gap in expectations and preparation might also pervade the graduate curriculum, which is usually research-oriented and not targeted toward industry careers. ${ }^{4}$ Since nearly $80 \%$ of engineering Ph.D. graduates will 
pursue a career in industry after graduation, ${ }^{5}$ this means that a vast number of Ph.D.-holding engineers in in industry may also be under-prepared at the time of graduation.

Previous research by the authors seeks to understand the KSAs that are most desired for Ph.D.holding engineers, both in industry and in academia. By interviewing 40 engineering professionals in both sectors, qualitative data analysis of the interviews converged upon approximately $47 \mathrm{KSAs}$ were converged upon as being necessary to be qualified and competent Ph.D.-level engineers. Some of these desired KSAs are technical competencies, technical leadership, and written and verbal communication skills (Authors, 2011). Similar studies regarding the need for alignment in graduate engineering education have echoed the need for $\mathrm{Ph}$.D. holding students that are good communicators, globally aware, technically competent, and understand business and management practices. ${ }^{6}$

However, few researchers study graduate engineering students' opinions of what is necessary for their future career success, and to what extent they feel their graduate studies have prepared them for success in future careers. If industry and academia are so affected by the lack of alignment, then students should be aware of these "gaps" in their education. This study seeks to answer the following research questions:

1. What are the primary knowledge, skills, and attributes that graduate students perceive to be the most important for their future career success?

2. How well do doctoral students believe the current graduate curriculum is preparing them for success in the areas that they identified?

Through this work, a survey was developed to capture graduate students regarding these research questions. Results of this survey are presented in this work.

\section{Literature Review}

Through the last decade, many researchers have noted a misalignment between knowledge, skills, and attributes desired by employers hiring engineering graduates and the skills which engineering possess upon graduation. This misalignment occurs both for engineers holding bachelor's degrees as well as in Ph.D. students and graduates, pursuing both industry and academic careers. Many studies have examined the desired skills of baccalaureate-level engineering graduates (usually from an industry perspective), ${ }^{3,71}$ resulting in improved standards for undergraduate education, represented in ABET accreditation criteria ${ }^{1}$ and publications such as the National Academy of Engineering's "Educating the Engineer of 2020.",2

To date, research that focuses on understanding perceptions of and expectations of baccalaureate-level engineers by industry and academia has been conducted by Austin (2002), Lang et al (2009), Martin et al (2005) and Nguyen (1998), but none of these papers address the specific perceptions of graduate engineering students regarding attributes in future desired careers. Austin and colleagues tracked graduate students over time to study student socialization into the necessary roles and development of skills to succeed in an academic career, but none of the discussion in the paper was framed around engineering specifically nor for careers in industry. ${ }^{12}$ Lang et al. (2009) conducted a survey of engineers in industry regarding the necessary attributes for entry-level (baccalaureate) engineers using a survey instrument asking participants about the importance of 172 characteristics based on the (then current) ABET 2000 
Criterion 3 categories, highlighting necessary skills for undergraduate engineering students like data analysis proficiency, teamwork skills and multidisciplinary communication, ability to identify problems and alternative solutions, and interpersonal skills (including written, verbal, presentation skills, and technical report writing). ${ }^{8}$ Martin et al. (2005) studied recent graduates' perceptions of how well they felt they had been prepared for careers in industry. Again, this study was conducted with recent graduates of bachelor's degree programs, rather than Ph.D. programs. Themes such as leadership, communication skills, life-long learning, business skills, teamwork, and interpersonal skills emerged from their qualitative interviews. ${ }^{7}$ Nguyen (1998) distributed a survey regarding the essential skills and attributes of an engineering to practicing engineers in academia and industry, and to engineering students in order to compare the emphases on specific attributes required for an engineer of the three groups, including elements of competence, engineering fundamentals and application, environmental constraints, quality control, technical knowledge, and economic and political issues. ${ }^{11}$

Less work has been done at the level of graduate education. There is general agreement about the lack of preparation for engineering careers in both industry and academia of Ph.D. students, as a result of the high level of specificity and focus on research from most doctoral engineering programs. ${ }^{4,13}$ This misalignment can be avoided through faculty and university intervention in identifying and developing the skills and knowledge that Ph.D. students need to have before they leave their graduate studies: Many improvements have been suggested in literature to avoid this issue. ${ }^{14-19}$ Previous work by the authors and others have studied specific characteristics that are necessary for success in industry and academic careers for Ph.D.-holding students. ${ }^{16,18,20}$ Watson and Lyons (2011) studied engineering industry job solicitations in order to determine the most highly-requested skills for Ph.D.s working in industry. ${ }^{13}$ These recommendations reflect the point of view of professionals working in the field.

The work by these researchers is useful; however, the lack of research that examines graduate students' perspectives on the skills they require for professional success is concerning. If graduate students' views of what skills are important for them to develop during their graduate training do not align with the mission of faculty and professionals, they make be less likely to engage in the most effective training and development opportunities. If graduate student perspectives differ significantly from those of professional engineers, it may cause them to focus on the development of skills that will not serve them in securing employment or advancing in their careers. The purpose of the current study is to explore from the graduate student perspective the knowledge, skills, and attributes that are essential to career success and the degree to which they feel their graduate training will prepare them in each area, which could help to guide universities in adapting doctoral program goals to accommodate a diverse set of skills, such as communication, business skills, and a focus on teamwork and management, as well as technical expertise.

\section{Methods}

Seventy-seven graduate students (35\% women) enrolled in doctoral engineering programs at a large Midwestern university voluntarily completed an online survey assessing the level of importance and preparation of potential skills and abilities relevant to their future careers. We were interested in differences based on the sector in which students intended to work. Of the 
respondents, $27 \%$ intended to work in academia, 57\% intended to work in industry, and $13 \%$ intended to work in government. Because previous research has focused on academia and industry, we chose to focus only on participants who intended to work in these areas. The following analyses are based on only those students, which consisted of 67 respondents (87\% of the original sample.)

The survey was designed to determine what knowledge, skills, and attitudes graduate students in engineering fields believe to be necessary to career success and to what degree they believe those KSAs will be developed during their graduate training. The survey items are based on data from a larger study collected for a National Science Foundation (NSF) project that focused on the preparation of engineering doctoral students for careers in academia and industry. During the course of an interview, forty engineering Ph.D. holders working in industry and academia were asked to identify their roles and expectations within their work settings and their views on important characteristics and attributes that Ph.D. engineers should possess. Each interview transcript was coded by a trained coder at two levels. The primary codes included Characteristics of Engineers, Expectations of Engineers, and Recommendations for Doctoral Education. Each of these general codes then had a number of secondary codes that identified specific skills and abilities (e.g., communication, technical knowledge, etc.).

To develop the current survey we identified the top five most frequent secondary codes under each of the three primary codes. Researchers then reviewed the interview responses associated with each of those codes. These responses formed the basis for the knowledge, skills, and attributes (KSA) statements used in the current questionnaire. Because professionals from industry were underrepresented in the initial set of interviews, additional KSAs relevant to engineering careers in industry were included based on work by Watson and Lyons (2011). ${ }^{13}$

The survey included two sets of questions related to the most frequent KSAs identified in the original interviews. The root for the first question was:

Please rate how important each task, skill, and ability is to your successful job performance after completing your Ph.D. Please think about this in terms of your future career role (not your experience now as a graduate student). For example, if the item is "communicate in writing," you are assessing how important communicating in writing will be in your future career.

This root was followed by the list of skills and abilities. A 5-item Likert response scale was provided. Response options included 1 (Not important), 2 (Minimally important), 3 (Somewhat Important), 4 (Important), and 5 (Extremely Important). The root for the second question was:

For each of the tasks, skills, and abilities listed, please indicate how well your Ph.D. program has prepared (or will prepare you) in each area.

Participants rated each item on a 5-point Likert scale. Responses options included 1 (Not at all prepared), 2 (Minimally prepared), 3 (Somewhat prepared), 4 (Adequately prepared), and 5 (Expertly prepared). 
Data were analyzed using a numerical comparison of the average rankings of each of the 90 skills and attributes identified by the participants in the study. The data will be useful in comparing the knowledge "gaps" identified by students to gaps that have been identified by engineers established in academic or industry careers, as well as to validate the need for graduate level engineering education research and reform to mitigate these gaps.

\section{Results}

In order to analyze the knowledge, skills, and attributes that graduate students perceive to be important to successful job performance after completing a doctoral degree, we compared the top-ranking KSAs for the students who identified as having career aspirations in academia, and the top-ranking KSAs for the students who anticipate going into engineering industry professions. Table 1 shows the top ten ranked KSAs for each of these groups of students. Any items which received the same mean score on importance received the same ranking. The skills ranked as most important for academia, for example, have four skills that tied for the rank of 3. For participants who intended to pursue careers in academia, there were multiple cases of items receiving equal mean ratings, resulting in a longer "top 10" list of KSAs for that group, as compared to the group of students intending to work in industry.

Table 1: Comparison of the top-ranking knowledge, skills, and attributes predicted as necessary for career success by students anticipating jobs in industry versus academia

\begin{tabular}{|c|c|c|c|c|c|}
\hline \multirow{2}{*}{$\begin{array}{c}\text { Rank } \\
1 \\
\end{array}$} & \multicolumn{2}{|l|}{$\begin{array}{l}\text { Importance to future successful job performance } \\
\text { (Academia) }\end{array}$} & \multirow{2}{*}{$\begin{array}{c}\text { Rank } \\
1 \\
\end{array}$} & \multicolumn{2}{|c|}{$\begin{array}{l}\text { Importance to future successful job performance } \\
\text { (Industry) }\end{array}$} \\
\hline & $\begin{array}{l}\text { Break down complex concepts into simple, } \\
\text { understandable ideas }\end{array}$ & 4.81 & & Solve problems & 4.77 \\
\hline 2 & Communicate orally & 4.76 & 1 & Meet deadlines & 4.77 \\
\hline 3 & Learn independently & 4.71 & 2 & $\begin{array}{l}\text { Be able to adapt and learn new } \\
\text { technologies }\end{array}$ & 4.75 \\
\hline 3 & Review literature & 4.71 & 3 & Work in teams & 4.68 \\
\hline 3 & Communicate in writing & 4.71 & 3 & Communicate orally & 4.68 \\
\hline 3 & Communicate with a variety of audiences & 4.71 & 4 & Possess strong analytical ability & 4.66 \\
\hline 4 & Tailor communication to your audience & 4.67 & 5 & Communicate in writing & 4.64 \\
\hline 5 & Motivate others & 4.62 & 5 & $\begin{array}{l}\text { Break down complex concepts into simple, } \\
\text { understandable ideas }\end{array}$ & 4.64 \\
\hline 5 & Present at professional conferences & 4.62 & 6 & Approach problems systematically & 4.61 \\
\hline 5 & Promote your work & 4.62 & 6 & Tailor communication to your audience & 4.61 \\
\hline 6 & Possess strong analytical ability & 4.57 & 7 & Interface with industry & 4.59 \\
\hline 6 & $\begin{array}{l}\text { Stay current on latest research and research } \\
\text { trends }\end{array}$ & 4.57 & 8 & Give presentations & 4.57 \\
\hline 6 & Solve problems & 4.57 & 9 & $\begin{array}{l}\text { Use multiple tools to solve complex } \\
\text { problems }\end{array}$ & 4.55 \\
\hline 6 & Meet deadlines & 4.57 & 10 & Manage multiple projects & 4.52 \\
\hline 6 & Bring in outside funding for research & 4.57 & 10 & Write technical reports & 4.52 \\
\hline 7 & Teach academic courses & 4.52 & 10 & Work across disciplines & 4.52 \\
\hline 7 & $\begin{array}{l}\text { Identify areas of research likely to receive } \\
\text { grant funding }\end{array}$ & 4.52 & & & \\
\hline 7 & Work independently & 4.52 & & & \\
\hline
\end{tabular}




\begin{tabular}{|c|l|c|l|l|l|}
\hline 7 & Give presentations & 4.52 & & & \\
\hline 8 & Identify others' strengths & 4.48 & & & \\
\hline 8 & $\begin{array}{l}\text { Possess in-depth knowledge about a specific } \\
\text { area }\end{array}$ & 4.48 & & & \\
\hline 8 & $\begin{array}{l}\text { Develop and manage budgets for research } \\
\text { projects }\end{array}$ & 4.48 & & & \\
\hline 8 & Synthesize information & 4.48 & & & \\
\hline 8 & Manage multiple projects & 4.48 & & & \\
\hline 8 & Write peer-reviewed papers & 4.48 & & & \\
\hline 9 & $\begin{array}{l}\text { Delegate tasks/projects based on others' } \\
\text { strengths }\end{array}$ & 4.43 & & & \\
\hline 9 & $\begin{array}{l}\text { Understand how your research fits into the } \\
\text { field more broadly }\end{array}$ & 4.43 & & & \\
\hline 9 & Create proposals & 4.43 & & & \\
\hline 9 & Write grant proposals & 4.43 & & & \\
\hline 10 & Work in teams & 4.38 & & & \\
\hline 10 & Find problems & 4.38 & & & \\
\hline 10 & Manage resources & 4.38 & & & \\
\hline 10 & Establish an independent lab/research group & 4.38 & & & \\
\hline
\end{tabular}

The biggest difference between the two groups is the number of top-ranking KSAs identified in the top ten ranks by students wanting to go into academia versus the number of KSAs identified as critical for students anticipating careers in industry. Future academicians identified 33 important KSAs, while future industry engineers identified only 16. This may indicate that students having ambitions to go into academia are acutely aware of the many roles (advisor, mentor, teacher, researcher, manager) in which professors and academic researchers are required to excel. This may also reflect a better understanding of the role of an academician because they are currently being socialized by the academic environment.

Most of the skills identified by students pursuing careers in industry overlapped with skills that future academicians identified to be important as well. These skills are highlighted in Table 1. Ten of the most important skills identified for industry were also identified by those in academia. Skills unique to those who intend to work in industry were overwhelmingly industry-specific, including "Be able to adapt and learn new technologies," "Interface with industry," and "Write technical reports."

The skills that were uniquely identified by students intending to work in academia tended to include skills that could be classified by roles, such as advisor and researcher. For example, many of the skills rated as important relate to managing/advising others, including "Identify others' strengths," "Motivate others," and "Delegate tasks/projects based on others' strengths." The second most common skills in this unique set related to acquiring research funding, including "Develop and manage budgets for research projects," "Bring in outside funding for research," and "Identify areas of research likely to receive grant funding." These are roles in which academic research advisors must excel in order to be successful, in addition to other skills in teaching and group management. 
The researchers are also interested in any differences that result between student's rankings of a KSA's importance versus how well they perceive they will be prepared for that skill. Looking toward the top KSAs identified by academically-oriented students, we can compare the numerical averages for importance and preparation. Figure 1 shows overall how students feel they will be prepared to take on the challenges of academia upon receiving their doctoral degree compared to the tasks they ranked as most important.

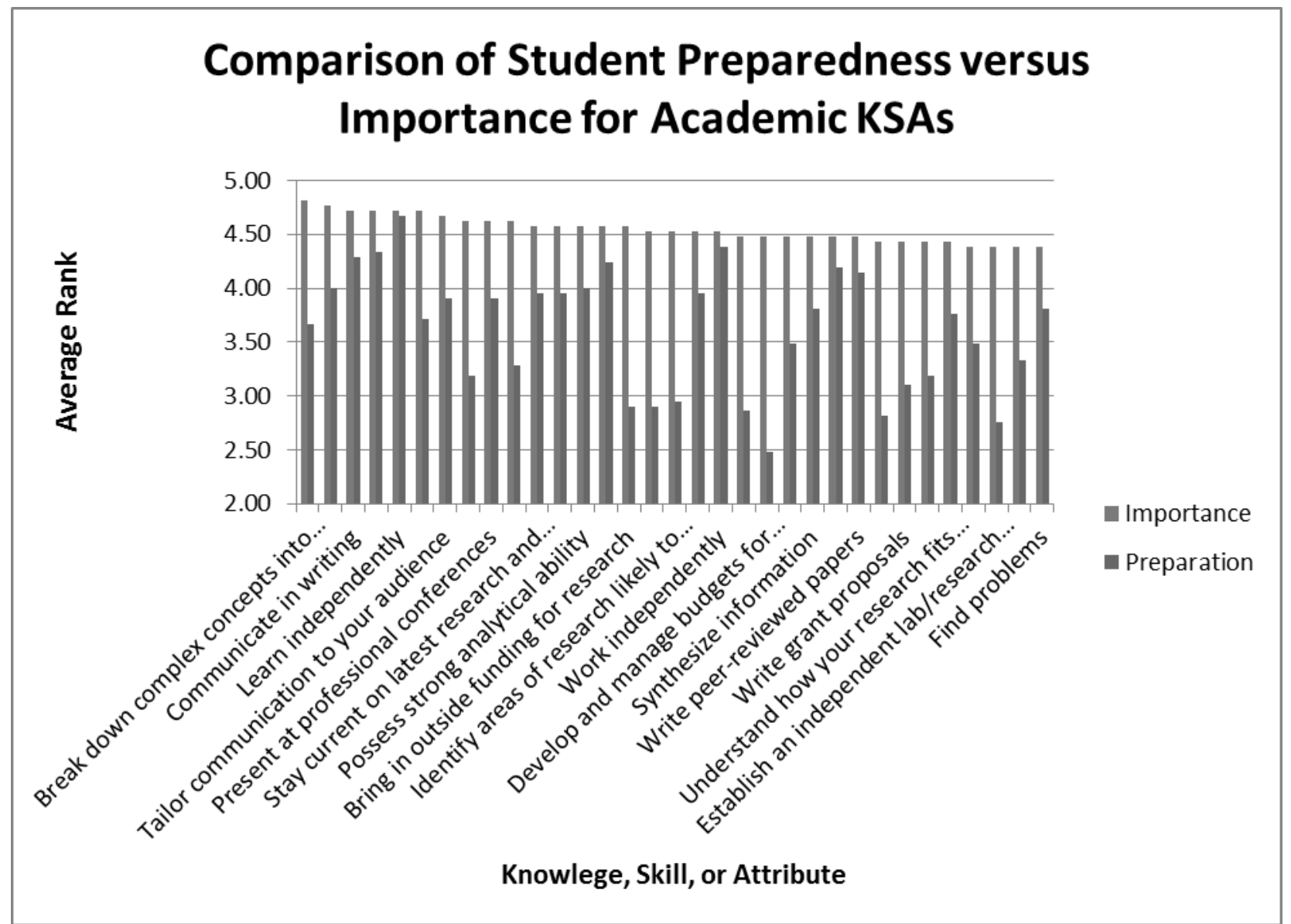

Figure 1: Comparison of Preparedness versus Importance of critical knowledge, skills, and attributes (Academia)

The KSAs with the largest differences between Importance and Preparation can be interpreted as the skills which doctoral students identified as being the biggest "gaps" in their personal goals for doctoral education as a preparation for their future careers. The trait that students feel most prepared for is their ability to "Learn independently" in an academic setting, followed closely by "Work independently."

Table 2 shows a chart of the traits with the largest differences in the importance and preparation scores. The KSAs that are shown here all have an average difference greater than one point on the five point scale. The negative sign indicates that students' mean rating of preparedness was less than the mean rating of importance. None of the KSAs resulted in positive differences, which would have meant that the mean rating of preparedness exceeded the mean rating of importance. 
Table 2: Largest differences between preparedness and importance scores for top-ranking academic KSAs.

\begin{tabular}{|l|c|}
\hline \multicolumn{1}{|c|}{ Knowledge, Skill, or Attribute (KSA) } & Difference \\
\hline Develop and manage budgets for research projects & -2.00 \\
\hline Bring in outside funding for research & -1.67 \\
\hline Establish an independent lab/research group & -1.62 \\
\hline Teach academic courses & -1.62 \\
\hline Delegate tasks/projects based on others' strengths & -1.62 \\
\hline Identify others' strengths & -1.62 \\
\hline Identify areas of research likely to receive grant funding & -1.57 \\
\hline Motivate others & -1.43 \\
\hline Promote your work & -1.33 \\
\hline Write grant proposals & -1.33 \\
\hline Create proposals & -1.24 \\
\hline Break down complex concepts into simple, understandable & \\
ideas & -1.14 \\
\hline Manage resources & -1.05 \\
\hline Communicate with a variety of audiences & -1.00 \\
\hline Manage multiple projects & -1.00 \\
\hline
\end{tabular}

It is interesting to note that the skills that were rated uniquely by students intending to work in academia as important (i.e., skills related to advising others and securing research funding) are also many of the skills for which they feel least prepared. This can be interpreted to mean that although academia socializes students to be prepared for academic positions (one of the main critiques of doctoral engineering education) students may not feel prepared to perform two of the main roles of academic researchers and the professoriate. It cannot be concluded that students are "underprepared" in these skills, because "underpreparedness" is relative to the goals of doctoral program; however, the differences in the scores indicate that students believe they have less experience in these important roles when they begin their careers.

The same comparisons were also conducted for students pursing engineering careers in industry after their doctoral work. The results of this data analysis are shown in Figure 2. 


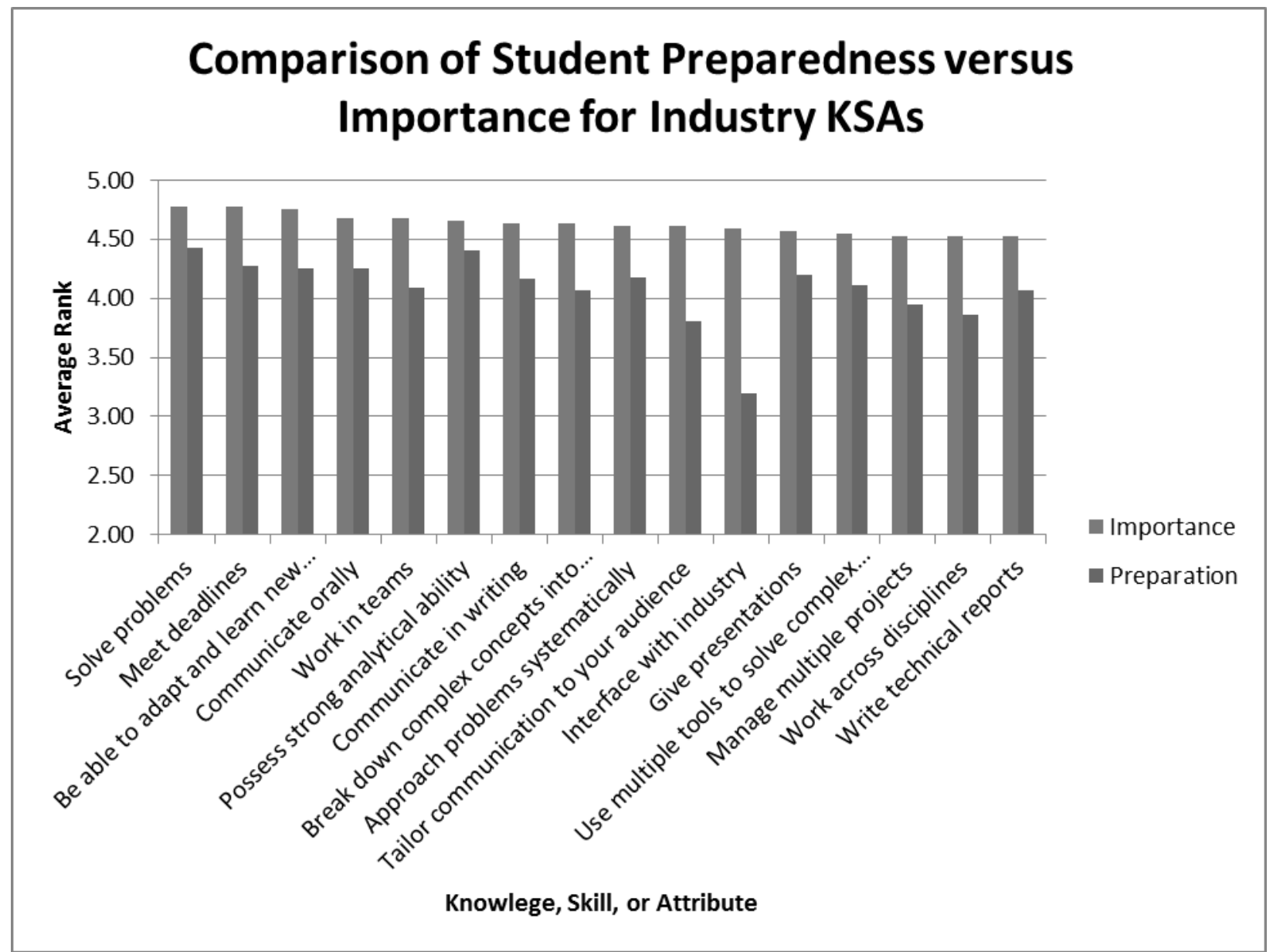

Figure 2: Comparison of Preparedness versus Importance of critical knowledge, skills, and attributes (Industry)

In general, as shown by Figure 2, students pursuing post-doctoral careers in industry had much less of a gap between their highest-ranked important skills and their feelings of preparation in these areas than the students pursuing academia. This potentially might be due to limited understanding of the depth of industry careers or student's inexperience working with industry. In fact, the largest gap between industry preparedness and importance was seen in the "Interface with industry" category. This is not unexpected, especially if the engineering graduate student has not been exposed to jobs or internships in an industry setting. Table 2 shows a chart giving the largest gaps that had a net difference of more than 0.4 points.

Table 3: Largest differences between preparedness and importance scores for top-ranking industry KSAs

\begin{tabular}{|l|c|}
\hline \multicolumn{1}{|c|}{ Knowledge, Skill, or Attribute (KSA) } & Difference \\
\hline Interface with industry & -1.39 \\
\hline Tailor communication to your audience & -0.81 \\
\hline Work across disciplines & -0.66 \\
\hline Work in teams & -0.59 \\
\hline Manage multiple projects & -0.57 \\
\hline
\end{tabular}




\begin{tabular}{|c|c|}
\hline $\begin{array}{l}\text { Break down complex concepts into simple, understandable } \\
\text { ideas }\end{array}$ & -0.57 \\
\hline Meet deadlines & -0.50 \\
\hline Be able to adapt and learn new technologies & -0.50 \\
\hline Communicate in writing & -0.48 \\
\hline Write technical reports & -0.45 \\
\hline Use multiple tools to solve complex problems & -0.44 \\
\hline Approach problems systematically & -0.43 \\
\hline Communicate orally & -0.43 \\
\hline
\end{tabular}

The researchers also examined which skills students intending to work in industry felt most prepared in, from the entire list of 91 potential KSAs. Most of the skills that exhibited the lowest gaps (and therefore the highest preparedness-to-importance ratios) did exist in the top 10 ranked most important skills. For industry-bound students, although ranked lower than the "most important" skills, the only skills that appeared in the top 10 they felt most prepared for that were not in the top most important were "work independently," "learn independently," "possess indepth knowledge about a specific area," "Understand the scientific method," and "Review literature." These are fairly predictable areas for a doctoral student to exhibit confidence, because these are usually main learning outcomes and tenets of doctoral research programs in general.

\section{Discussion}

The data presented above indicate that doctoral students pursuing both industry and academic engineering careers are aware of potential gaps in their education as compared to the skills they anticipate being important. Our study is unique because it provides data on the student perception of the needed traits for career success. The major traits generally do correlate with the gaps of traditional doctoral programs found in literature. For example, academic themes like research group management and funding/grant writing skills have been discussed by other authors as being a downfall in the traditional engineering doctoral education model. From the point of view of industry, themes like multidisciplinary, teamwork, communication in all respects, and management skills have been identified many times in calls for alternative doctoral pedagogies for students planning to succeed in industry.

It is difficult to directly compare the results of this study with numerical results shown in similar studies. We are particularly interested with comparing our numerical findings through this survey with numerical findings about the most important skills for Ph.D.-holding engineering graduates in academia and industry. However, most studies look particularly at the experiences and employer expectations of baccalaureate-level engineers entering the field. For example, Lang et al. (2009) conducted a survey of engineers in industry regarding the necessary attributes for entry-level (baccalaureate) engineers using a survey instrument asking participants about the importance of 172 characteristics based on the (then current) ABET 2000 Criterion 3 categories, which were also shown as averages on a 5-point scale. The summary of non-discipline-based skills ranked as most important included data analysis proficiency, teamwork skills and multidisciplinary communication, ability to identify problems and alternative solutions, professional and ethical issues, interpersonal skills (including written, verbal, presentation skills, 
and technical report writing) and computer, information, and technology literacy skills ${ }^{8}$. Martin et al. (2005) studied recent graduates' perceptions of how well they felt they had been prepared for careers in industry. ${ }^{7}$ This study was also conducted with recent graduates of bachelor's degree programs, rather than Ph.D. programs. Themes such as leadership, communication skills, life-long learning, business skills, teamwork, and interpersonal skills emerged from their qualitative interviews. Nguyen (1998) distributed a survey regarding the essential skills and attributes of an engineering to practicing engineers in academia and industry, and to engineering students in order to compare the emphases of specific attributes for each of the three groups ${ }^{11}$. There was no definition if the student involved either undergraduate students, graduate students, or a mix. This research showed different understandings of what attributes are required to be an engineer. The themes in common for the three groups of stakeholders in this study are as follows: Competence, engineering fundamentals and application, environmental constraints, quality control, technical knowledge, and economic and political issues. Traits shared between students and academicians additionally shared language fluency. In these findings, students did not identify as communication skills being an important aspect of engineering. ${ }^{11}$

Our data similarly assesses student perceptions of the skills that will be important, but also takes into account the career goals (industry or academia) of the respondents, as well as looking specifically at $\mathrm{Ph}$.D. engineering students. Many of the traits identified as important by industry professionals for entry-level engineers to possess do map to skills that industry-aspiring doctoral students think are important for future career success, especially "Solve problems," "Be able to adapt and learn new technologies," "Work in teams," "Communicate orally," "Possess strong analytical ability," "Communicate in writing," "Give presentations," "Use multiple tools to solve complex problems," "Write technical reports," and "Work across disciplines." Some of the other highly ranked important KSAs identified in our study may be more applicable to Ph.D.-level engineers, who would not be working in the same position as an engineer just out of her or his undergraduate degree.

As a final comparison with our results to previously-conducted studies, we return to Watson and Lyons for frequency of industry students' perceived important skills as compared to the identified knowledge, skills, and attributes identified from engineering industry job solicitations in their study. This is not a perfect comparison, because some of the Watson and Lyons themes were used to fortify the industry-specific questions in our survey. However, it is interesting to correlate the importance of the same themes as decided by current graduate students interested in industry careers with the frequency of characteristics found in Watson and Lyons' study. ${ }^{13}$ Of the industry KSAs ranked most important by current Ph.D. students, problem solving skills appeared in $69 \%$ of engineering job solicitations studied; teamwork, $88 \%$; communication skills, $82 \%$; and multidisciplinary teamwork, $66 \%$. Although the study does not directly map to our findings, it can be seen that in general, students' value of the KSAs needed for academia for the most part comply with industry values as well.

One important discussion point that was not addressed in this study was the effect of relative importance of a student to their perception of preparation. For example, one critique of doctoral education is that since students are socialized into a research-heavy role, they underestimate the importance of the teaching part of their job. In our findings, please note that none of the KSAs ranked in the top ten were related to classroom teaching, which is one of the most influential 
roles of a professor in the lives of students. In this study, we did not probe whether or not the role of a teacher is undervalued in students pursuing academic careers, but the data show that teaching skills are not among the "most important" as we defined them in this study. In future work, it would be interesting to explore this aspect of doctoral education and student perceptions of preparation for roles they deem relatively unimportant as compared to research roles.

\section{Conclusion}

The survey conducted in this study sought to examine graduate student perceptions of the necessary knowledge, skills, and attributes (KSAs) needed for future engineering careers in academia or industry. Students were given an online survey which consisted of 90 potential traits which the student was instructed to rank on a five-points scale for level of importance and how prepared the student felt they would be in the area at degree completion. Analysis of the most important KSAs were compared for students pursuing a career in academia and students anticipating a career in industry. It was found that among the top ranked items, students focused on academic careers identified twice as many critically important KSAs they felt would be necessary for career success. Student perception of preparation in each of the identified KSAs was also reported for both academia- and industry-bound $\mathrm{Ph}$.D. students. Overall, students in academia rated their preparedness in the identified most important categories much lower than did the students interested in industry. Through this analysis, it was determined that on average, the academic students perceive their "gaps" in most important areas of future careers to be related to budgeting and research group management. Students in industry had fewer areas with significantly low areas of perceived preparedness. This research should be compared with other studies from employer points of view in order to best identify the shortcomings of traditional doctoral engineering education and identify potential remedies. Further research should be done to directly map student perceptions to the needs of employers in industry as well as in academia. The findings from our study indicate that there is a difference in the goals of students intending to pursue careers in academia and industry, and indicate that in future studies, career goal is an aspect that should be addressed by researchers comparing the preparation of students with engineering employer expectations.

\section{References}

Authors (2011). Removed for blind review.

1. ABET. Criteria for accrediting engineering programs: Effective for reviews during the 2014-2015 accreditation cycle. (2013). at 〈http://www.abet.org>

2. NAE. The engineer of 2020: Visions of engineering in the new century. (2004). at <http://www.nap.edu>

3. American Society for Engineering Education. Transforming Undergraduate Education in Engineering. 1-50 (2013). at <http://www.asee.org/TUEE_PhaseI_WorkshopReport.pdf>

4. Akay, A. A renaissance in engineering PhD education. Eur. J. Eng. Educ. 37-41 (2008). at <http://www.tandfonline.com/doi/abs/10.1080/03043790802253475>

5. Schillebeeckx, M., Maricque, B. \& Lewis, C. The missing piece to changing the university culture. Nat. Biotechnol. 31, 938-41 (2013). 
6. Nair, C. \& Patil, A. Industry vs universities: re-engineering graduate skills-a case study. Qual. Stand. High. Educ. ... 1-7 (2008). at <http://works.bepress.com/cgi/viewcontent.cgi?article=1014\&context=hamish_coates\#page=85>

7. Martin, R., Maytham, B., Case, J. \& Fraser, D. Engineering graduates' perceptions of how well they were prepared for work in industry. Eur. J. Eng. Educ. 30, 167-180 (2005).

8. Lang, J. D., Cruse, S., McVey, F. D. \& McMasters, J. Industry Expectations of New Engineers : A Survey to Assist Curriculum Designers. J. Eng. Educ. 43-51 (1999).

9. Joe, P. \& Bucknell, T. The T-shaped Engineer : Connecting the STEM to the TOP The T-shaped Engineer : Connecting the STEM to the TOP Section 1 : Practical Barriers. (2013).

10. Darling, A. L. \& Dannels, D. P. Practicing Engineers Talk about the Importance of Talk: A Report on the Role of Oral Communication in the Workplace. Commun. Educ. 52, 1-16 (2003).

11. Nguyen, D. The essential skills and attributes of an engineer: a comparative study of academics, industry personnel and engineering students. Glob. J. Eng. Educ. 2, (1998).

12. Austin, A. E. Preparing the Next Generation of Faculty: Graduate School as Socialization to the Academic Career. J. Higher Educ. 73, 94-122 (2002).

13. Watson, J. \& Lyons, J. Aligning Academic Preparation of Engineering Ph.D. Programs with the Needs of Industry. Int. J. Eng. Educ. 27, 1394-1411 (2011).

14. Salters, R. E. Pursuing the Ph.D. in the Sciences and Engineering: Trends and Observations. New Dir. High. Educ. 1997, 91-97 (1997).

15. Wallgren, L. \& Hägglund, S. The industry doctoral student-An educational challenge for academia and industry. Creat. Knowl. Environ. ... 1-16 (2004). at <http://books.google.com/books?hl=en\&lr=\&id=f7oxVgBdsh8C\&oi=fnd\&pg=PA104\&dq=The+Industry+ Doctoral+Student+-

+ An+educational+challenge+for+academia+and+industry\&ots $=$ uULnzLs4FO\&sig=79I05WJ5uatn5OiCeOb gCW6BJJw>

16. Akay, A. A renaissance in engineering PhD education. Eur. J. Eng. Educ. 33, 403-413 (2008).

17. Neumann, R. Doctoral Differences: Professional doctorates and PhDs compared. J. High. Educ. Policy Manag. 27, 173-188 (2005).

18. Austin, A. E., Connolly, M. R. \& Colbeck, C. L. Strategies for Preparing Integrated Faculty: The Center for the Integration of Research, Teaching, and Learning. 69-82 (2001). doi:10.1002/tl

19. Golde, C. M. Applying Lessons from Professional Education to the Preparation of the Professoriate. 17-26 doi:10.1002/tl

20. Colbeck, C. L. Professional Identity Development Theory and Doctoral Education. 9-17 (2000). doi:10.1002/tl 